\title{
REINTERPRETAÇÃO DA AMBIÊNCIA TECTÔNICA DE FORMAÇÃO DO LEUCOGRANITO DE GOUVEIA (MINAS GERAIS)
}

\author{
Alexandre de Oliveira Chaves ${ }^{1}$, Raphael Martins Coelho ${ }^{1}$ \\ 1- Departamento de Geologia - Centro de Pesquisas Manoel Teixeira da Costa - Instituto de Geociências - Universidade Federal de Minas Gerais \\ (CPMTC-IGC-UFMG). alochaves@yahoo.com.br; raphaelmcoelho@yahoo.com.br \\ Recebido em 20 de janeiro de 2018; aceito em 20 de junho de 2018
}

Resumo: Granitoides podem se formar não apenas nos vários ambientes dos diferentes estágios do ciclo de Wilson, como também acima de plumas mantélicas, como resultado da fusão crustal decorrente do calor fornecido pelas plumas. Com base na geoquímica e geocronologia disponível na literatura, este artigo leva em conta essa última possibilidade na reinterpretação do ambiente tectônico de formação do leucogranito de Gouveia (Minas Gerais), que havia sido previamente interpretado como granitoide de ambiente tectônico colisional.

Palavras Chave: Granito tipo-A, Gouveia, fusão crustal

Abstract: TECTONIC SETTING OF THE GOUVEIA LEUCOGRANITE (MINAS GERAIS) REINTERPRETED. Granitoids can be originated not only in the diverse tectonic settings of the Wilson Cycle, but also above mantle plumes, as a result of the crustal melting promoted by heat transfer from plumes. Based on geochemistry and geochronology available in literature, this paper takes this possibility into account on the reinterpretation of the Gouveia leucogranite tectonic setting, previously interpreted as collisional.

Keywords: A-type granite, Gouveia, crustal melting

\section{INTRODUÇÃO}

Chaves \& Coelho (2013), em seu artigo intitulado "Petrografia, geoquímica e geocronologia do leucogranito peraluminoso do complexo de GouveiaMG", sugeriram que a geoquímica deste granito a duas micas com granada (Figura 1) aproximava sua gênese à dos granitos de ambiente de colisão continental ou da tectônica transcorrente a ela associada. Entretanto, a idade de 1811 +/- $32 \mathrm{Ma}$ encontrada por estes autores por meio da datação química U-Th-Pb em cristais de monazita situados no interior de K-feldspatos desta rocha diverge da fase colisional do evento Riaciano-Orosiriano regional, datada em torno de 2,1 Ga (Alkmim \& Marshak, 1998). Daí decorre um aparente equívoco na interpretação feita como colisional por Chaves \& Coelho (2013) para o leucogranito de Gouveia.

A

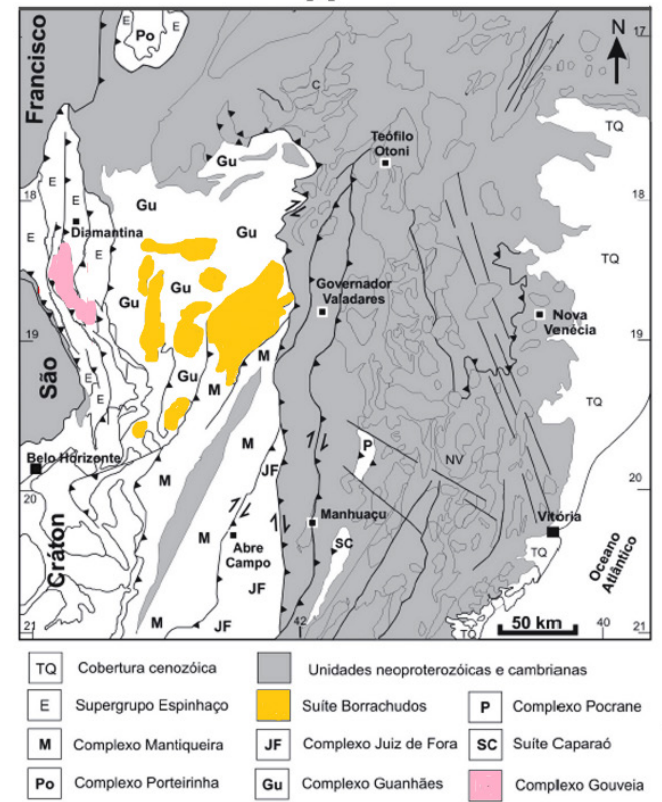

B

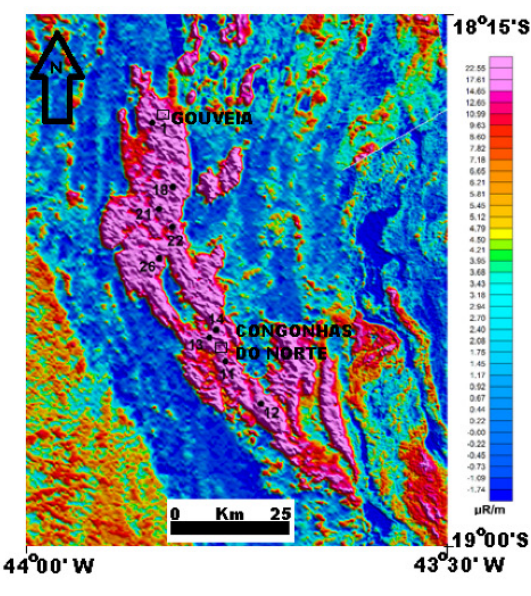

Figura 1. A) O Orógeno Araçuaí e seus complexos de embasamento (Noce et al., 2007). Em destaque, o Complexo de Gouveia e a suíte Borrachudos. B) Imagem gamaespectrométrica - contagem total U-Th-K (CODEMIG, 2012), onde o leucogranito de Gouveia, mais rico em $U$, Th e $K$ que as rochas circundantes, aparece em rosa. Dosagem de radiação gama em microRoentgen/minuto ( $\mu R / \mathrm{m})$. Os pontos com análises litogeoquímicas realizadas por Chaves \& Coelho (2013) estão apresentados na imagem. 
Li et al. (2003) e Xu et al. (2008) demonstraram que granitoides podem se formar não apenas nos vários ambientes geotectônicos dos diferentes estágios do ciclo de Wilson, como também acima de plumas mantélicas, a partir da fusão de crosta préexistente decorrente do calor fornecido pelas plumas. Li et al. (2003) mostraram que granitoides do sul da China com diferentes características geoquímicas e isotópicas foram cristalizados após anatexia crustal disparada pelo calor de uma pluma mantélica quando esta atingiu a litosfera daquele local.

Este artigo pretende reinterpretar a ambiência tectônica de formação do leucogranito de Gouveia (Minas Gerais), sugerida como colisional por Chaves \& Coelho (2013), sob a luz da geoquímica de rochas granitoides provenientes de fusão crustal associada a plumas mantélicas. Esta reinterpretação encontra-se apoiada em estudo recente feito por Chaves et al. (2016), o qual sugere que a região onde o referido leucogranito está localizado teria sofrido a influência termodinâmica da atividade de uma possível pluma mantélica por volta de 1,8 Ga.

\section{REINTERPRETAÇÃO DOS DADOS GEOQUÍMICOS DO LEUCOGRANITO DE GOUVEIA}

O complexo de Gouveia é constituído essencialmente por uma massa de leucogranito peraluminoso anatético, muitas vezes porfirítico, com fenocristais centimétricos de feldspato potássico (Hoffmann, 1983). Este leucogranito é facilmente distinguido de suas rochas encaixantes em imagem gamaespectrométrica (Figura 1B) por ser mais rico em $U$, Th e $\mathrm{K}$ do que elas. Eventualmente são encontrados restos de migmatitos paraderivados no seu interior em contato transicional difuso. Machado et al. (1989) encontraram idades U-Pb em zircão de 1844 +/- $15 \mathrm{Ma}$ (intercepto inferior da discórdia) e 2839 +/- 14 Ma (intercepto superior da discórdia) para o leucogranito. O valor encontrado de 1811 +/32 Ma por Chaves \& Coelho (2013) para o evento anatético e cristalização do magma leucogranítico de Gouveia é similar, dentro da margem de erro, ao valor da idade isotópica U-Pb em zircão de 1844 +/- $15 \mathrm{Ma}$ de Machado et al. (1989). A idade de 2839 +/- $14 \mathrm{Ma}$ também encontrada por estes últimos autores poderia ser atribuída a núcleos de zircões herdados do protólito migmatítico arqueano do leucogranito. A propósito, Silva et al. (2002) encontraram uma idade de 2867 +/- 10 Ma para os gnaisses migmatíticos do vizinho Complexo Guanhães (Figura 1A), cuja anatexia no período Estateriano teria gerado os granitos Borrachudos.

Segundo Chaves \& Coelho (2013), nove amostras estudadas do leucogranito de Gouveia, que correspondem a álcali-feldspato granitos em termos modais, são rochas peraluminosas, com coríndon normativo. Variam de granitos alcalinos a álcalicálcicos. A elevada razão $\mathrm{K} / \mathrm{Na}$, alto teor de $\mathrm{SiO} 2$ e baixos conteúdos de $\mathrm{Ca}$ (e $\mathrm{Sr}$ ), associados ao seu caráter peraluminoso e à presença de biotita e muscovita primárias, levaram a chamá-los de tipo $\mathrm{S}$ na classificação de Chappell e White (1992), ou seja, resultantes de anatexia de material crustal essencialmente paraderivado.

O diagrama de elementos terras-raras normalizados ao condrito (Figura 2A) mostra padrão de similaridade das amostras entre si e destas com os leucogranitos peraluminosos colisionais Himalaianos e Hercinianos de Harris et al. (1986). A característica colisional dos leucogranitos é reforçada pelo diagrama de elementos incompatíveis normalizados aos granitos de cadeia oceânica (Figura 2B), tendo em vista que o padrão do leucogranito de Gouveia é similar ao dos granitos sin-colisionais (colisão continente-continente) de Pearce et al. (1984). Estas feições, em conjunto com os diagramas tectônicos $\mathrm{Hf}-\mathrm{Rb} / 30-\mathrm{Tax} 3$ (Harris et al., 1986) e SiO2-Ta (Pearce et al., 1984), nos quais os granitos são classificados como sin- a tardi colisionais, sugeriram a Chaves \& Coelho (2013) que a anatexia crustal teria ocorrido em função do espessamento crustal e cisalhamentos regionais associados, durante ou logo após o clímax de um evento de colisão de massas continentais.

Entretanto, quando se observa o padrão de elementos terras-raras e elementos incompatíveis de granitoides diversos do sul da China, de gênese associada a processos de anatexia crustal disparada pelo calor de uma pluma mantélica (Li et al., 2003), percebe-se que guardam muitas semelhanças com o padrão dos granitos peraluminosos colisionais de Harris et al. (1986) e Pearce et al. (1984), aos quais o leucogranito de Gouveia foi associado (Figura 2 A e B) por Chaves \& Coelho (2013). A partir das semelhanças dos padrões dos leucogranito de Gouveia e dos granitos chineses mencionados, surge a possibilidade de relacionar a gênese do leucogranito de Gouveia ao aporte térmico trazido pela pluma mantélica sugerida por Chaves et al. (2016).

Apenas dois dos diversos diagramas de classificação de ambiência geotectônica de Pearce et al. (1984) sugerem que os leucogranitos de Gouveia sejam do tipo A, denominado anorogênico intraplaca. Ambos infelizmente não foram utilizados por Chaves \& Coelho (2013) e agora estão apresentados nas Figuras 3A e 3B. Esta classificação tectônica é reforçada pelo fato de dois terços das amostras analisadas do leucogranito de Gouveia caírem entre os campos pós-orogênico e anorogênico no diagrama multicatiônico R1-R2 (Batchelor \& Bowden, 1985 Figura 3C). Em sendo do tipo A, o diagrama Y-Nb-Ce (Figura 3D) de Eby (1992) classificaria o leucogranito de Gouveia como sendo do subtipo A2, considerado 
como granito derivado de fusão parcial de crosta continental ou crosta tipo arco magmático.
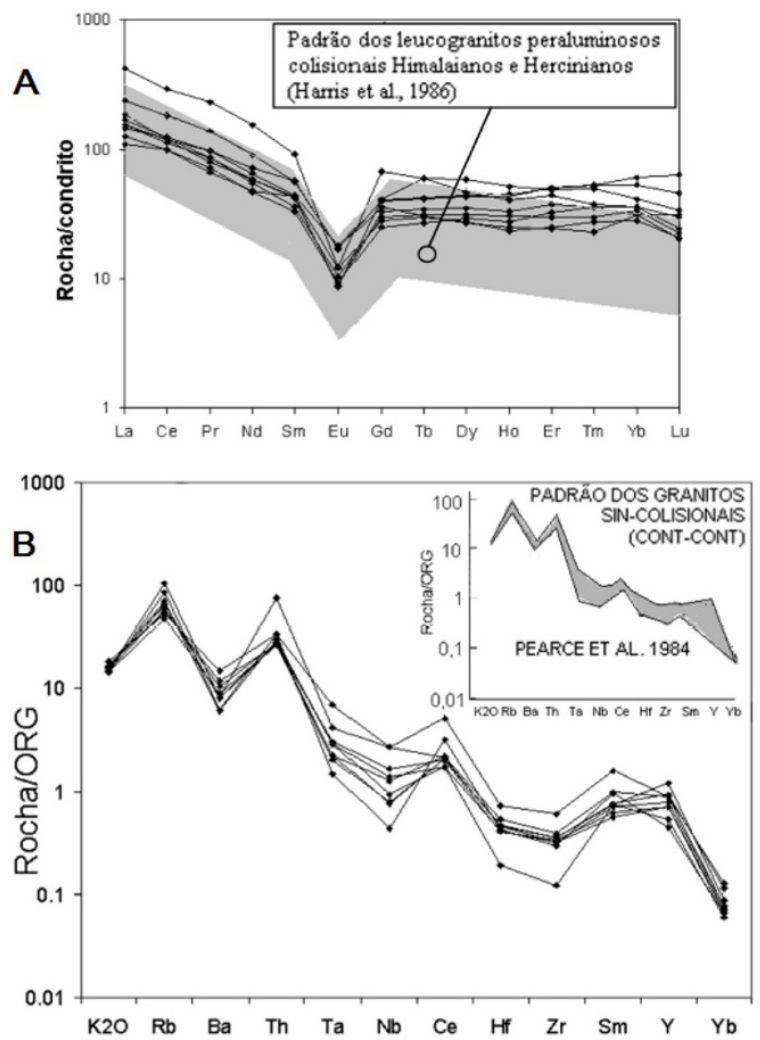

Figura 2. A) Diagrama de elementos terras-raras normalizado ao condrito dos leucogranitos de Gouveia. B) Diagrama de elementos incompatíveis normalizados aos granitos de cadeia oceânica (ORG) dos leucogranitos de Gouveia. O padrão dos granitos sincolisionais (colisão continente-continente) de Pearce et al. (1984) está apresentado para comparação (Chaves \& Coelho, 2013).
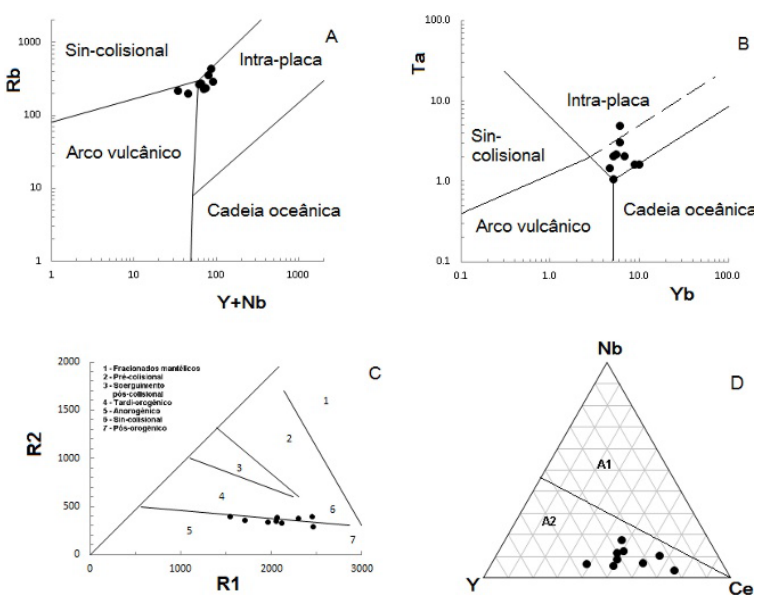

Figura 3. A) e B) Diagramas de classificação geotectônica de granitoides $Y+N b$ versus $R b$ e $Y b$ versus Ta de Pearce et al. (1984), com a plotagem das amostras do leucogranito de Gouveia. C) Diagrama multicatiônico R1-R2 (Batchelor \& Bowden, 1985). D) Diagrama triangular $\mathrm{Y}$-Nb-Ce de subdivisão de granitoides tipo $A$ de Eby (1992), com a plotagem das amostras do leucogranito de Gouveia. A1 - campo dos granitos derivados de cristalização fracionada de basaltos do tipo ilha oceânica. A2 - campo dos granitos derivados de fusão parcial de crosta continental ou crosta tipo arco.

\section{CONSIDERAÇÕES FINAIS}

Segundo Barbarin (1999), granitos peraluminosos acham-se fortemente associados a ambiente de colisão continental. Esta associação, em conjunto com o tratamento dos dados geoquímicos do leucogranito peraluminoso de Gouveia feito por Chaves \& Coelho (2013) com base nos trabalhos sobre granitoides não só de Barbarin (1999) como também nos de Harris et al. (1986) e de Pearce et al. (1984), induziram estes autores a interpretar equivocadamente seu contexto geotectônico como colisional durante sua petrogênese, e não como anorogênicos associados à plumas mantélicas.

Chaves et al. (2016) propuseram que os cratons Amazônico e São Francisco estiveram conectados entre 1,80 Ga e 1,77 Ga, quando sofreram a influência termodinâmica da atividade de uma possível pluma mantélica sob eles ancorada, cujo registro seriam enxames de diques máficos de uma província ígnea gigante (LIP - large igneous province), assim como a tafrogênese associada, a qual se relacionam sequências de rift como a do Espinhaço (Figura 4).

Da releitura e retratamento dos dados geoquímicos do leucogranito de Gouveia, é possível descartar sua relação a ambiente tectônico colisional e reinterpretar sua geração a partir de fusão de crosta continental representada pelo migmatitos de Gouveia de 2839 +/- 14 Ma (Machado et al., 1989). Este processo anatético datado nas monazitas inclusas em K-feldspatos do leucogranito em 1811 +/32 Ma por Chaves \& Coelho (2013) é de idade similar, dentro da margem de erro, ao de 1844 +/- $15 \mathrm{Ma}$ encontrado no intercepto inferior da discórdia $\mathrm{U}-\mathrm{Pb}$ em zircões desta mesma rocha (Machado et al., 1989) e está aparentemente associado ao aporte térmico da pluma mantélica sugerida por Chaves et al. (2016), apresentada na Figura 4. A propósito, este aporte térmico está documentado em 1,73 Ga em borda de cristal de titanita de monzonito de 1,95 Ga localizado na cidade de Gouveia (Chaves et al., 2015). A idade de 1,73 Ga provavelmente representa a idade de arrefecimento do aporte térmico, o qual teria tido uma duração de cerca de 70 a $80 \mathrm{Ma}$, correspondente ao período de atividade da pluma mantélica sob a crosta continental de Gouveia.

Esta reinterpretação leva em conta ainda o fato de que a idade de 1811 +/- 32 Ma do leucogranito de Gouveia é similar à idade de 1780-1730 Ma dos granitos da suíte Borrachudos e riolitos associados (Brito Neves et al., 1979, Dossin et al., 1993, Dossin et al., 2000), os quais podem ter sido gerados por fusão crustal disparada pela pluma sugerida por Chaves et al. (2016). Estes granitos Borrachudos estão localizados próximos ao leucogranito de Gouveia (Figura 1A) e são classificados por Fernandes et al. (1994) como anorogênicos (tipo A), alcalinos e de 
fusão crustal relacionada à abertura do rift Espinhaço. No craton Amazônico, leucogranitos peraluminosos tipo-A2 derivados de fusão crustal similares ao leucogranito de Gouveia, de idade em torno de 1,8 Ga, são encontrados no Pará (Teixeira et al., 2005) e no Mato Grosso (Barros et al, 2011; Prado et al., 2013) e apoiam a idéia de anatexia crustal disparada pelo calor da pluma mantélica apresentada na Figura 4.

Ao encerrar, cabe lembrar que plumas mantélicas ascendem pelo manto terrestre desde o limite manto-núcleo e, com sua chegada e permanência por cerca de 25 Ma à base da crosta continental, é promovida a fusão parcial da crosta ao afiná-la pelo processo de erosão térmica que eleva localmente a geoterma, atingindo a curva do solidus crustal (Davies, 1994).

\section{REFERÊNCIAS}

Alkmim, F.F. \& Marshak, S. 1998. The Transamazonian orogeny in the Quadrilátero Ferrífero, Minas Gerais, Brazil: Paleoproterozoic collision and collapse in the Southern São Francisco Craton region. Precambrian Research 90: 29-58.

Barbarin B., 1999. A review of the relationships between granitoid types, their origins and their geodynamic environments. Lithos 46: 605-626.

Barros, M.A.S., Pimentel, M.M., Rocha, M.L.B.P., Silva, F.R., Padilha, R.A., Dantas, E.L., Moura, E. 2011. A suite intrusiva Rio Dourado - um granito tipo-A de 1,88 Ga - sudeste do Craton
Amazônico - Mato Grosso - Brasil. Boletim IG-USP. Série Científica, 11(1):75-93.

Batchelor R.A. \& Bowden P. 1985. Petrogenetic interpretation of granitoid rock series using multicationic parameters. Chemical Geology 48:43-55.

Brito Neves, B.B., Kawashita, K., Delhal, J. 1979. A evolução geocronológica da Cordilheira do Espinhaço: dados novos e integração. Revista Brasileira de Geociências 9 (1): 71-85.

Chappell, B.W., White, A.J.R. 1992. I- and S-type granites in the Lachlan Fold Belt. Transactions of the Royal Society of Edinburgh, Earth Sciences 83: 1-26.

Chaves, A.O. \& Coelho, R.M. 2013. Petrografia, geoquímica e geocronologia do leucogranito peraluminoso do complexo de Gouveia-MG. Geonomos 21(2): 1-12.

Chaves, A.O., Scholz, R., Lana, C., Renger, F.E., Coelho, R.M., Dussin, T.M., Azevedo, M.R.M.A., Ribeiro, S.M. 2015. Datação da suíte alcalina e do magmatismo toleítico alto-K de Gouveia (MG): juntos no espaço mas distantes no tempo. Geociências (Unesp), 34 (3): 381-389.

Chaves, A.O., Fonseca, W.M., Leal, V.L.S. 2016. Províncias Ígneas Gigantes e o reposicionamento dos proto-crátons sulamericanos em Columbia, na transição Orosiriano-Estateriano. Boletim Museu Paraense Emílio Goeldi - Ciencias Naturais 11 (2): $263-280$

CODEMIG. Cia. Desenvolvimento Economico de Minas Gerais. 2012. Programa de Levantamento Aerogeofísico de Minas Gerais - Magnetometria e gamaespectrometria.

Davies G. (1994) Thermomechanical erosion of the lithosphere by mantle plume. Journal of Geophysical Research 99: 1570915722

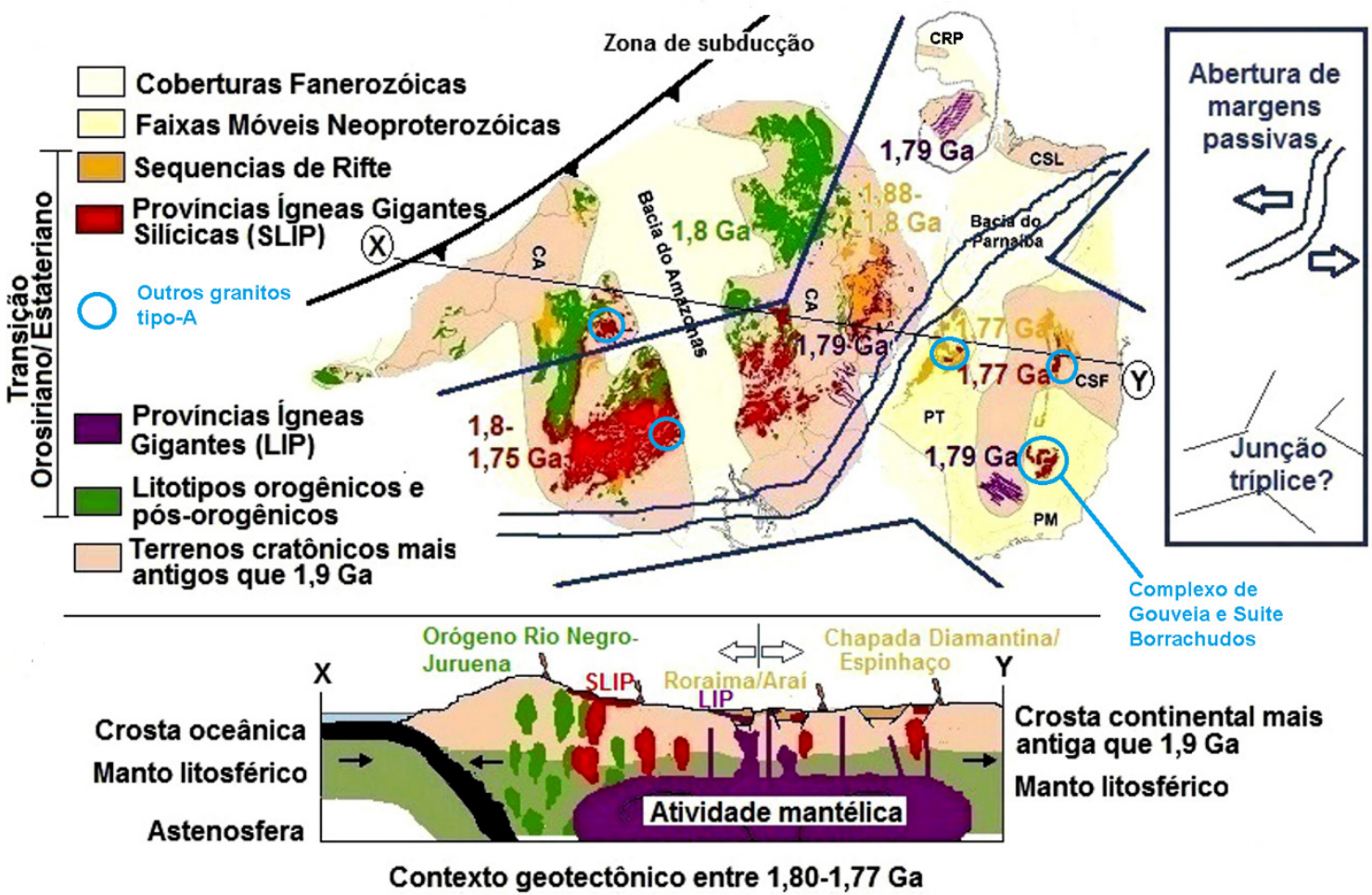

Figura 4. Possível configuração dos proto-crátons sul-americanos (CA - craton Amazônico, CSF - craton São Francisco, CSL - craton São Luis,

CRP - craton Rio de la Plata) e a junção tríplice com suas LIP e SLIP, que teriam sido geradas na transição Orosiriano-Estateriano (modificado de Chaves et al. 2016). Notar a localização do complexo de Gouveia e da suíte Borrachudos, bem como de granitos tipo-A do craton Amazônico nesta configuração. Abaixo: perfil esquemático $X-Y$, mostrando as atividades tectônica, magmática (associada à pluma mantélica e à zona de subducção contemporanea) e sedimentar, entre 1,8 Ga e 1,77 Ga. 
Dossin, I.A., Dossin, T. M., Charvet, J., Cocherie, A., Rossi, P. 1993. Single-Zircon dating by step-wise $\mathrm{Pb}$-evaporation of Middle Proterozoic magmatism in the Espinhaço Range, southeastern São Francisco Craton (Minas gerais, Brazil). Anais II Simp. Craton São Francisco, Salvador, p. 39-42.

Dossin, T. M., Duarte, P., Dossin, I.A. 2000. Registro da tectônica Brasiliana na região de Guanhães (SE, Brasil): Deformação e metamorfismo das rochas de idade pós-Transamazônicas. Geonomos 8(2): 55-59.

Eby, G.N. 1992. Chemical subdivision of the A-type granitoides: petrogenetic and tectonic implications. Geology 20: 641-644.

Fernandes, M. L. S., Marciano, V. R. P. R. O., Oliveira, R. C., Correia Neves, J. M., Diláscio, M. V. 1994. Granitos Borrachudos: um exemplo de granitogênese anorogênica na porção central do Estado de Minas Gerais. Geonomos 2(2): 23-29.

Harris N.B.W., Pearce J.A.,Tindle A.G., 1986. Geochemical characteristics of collision-zone magmatism. In: Coward, M.P. \& Ries, A. C. (eds). Collision Tectonics. Geological Society Special Publication 19: 67-81.

Hoffmann C. 1983. The Archean peraluminous Gouveia Granite: its structures, geochemistry and phase petrology (Serra do Espinhaço, Minas Gerais, Brazil). N. Jb. Min., 2: 359-371.

Li, X.H., Li, Z.X., Ge, W., Zhou, H., Li, W.,Liu, Y., Wingate, M.T.D. 2003. Neoproterozoic granitoids in South China: crustal melting above a mantle plume at ca. $825 \mathrm{Ma}$ ? Precambrian Research, 122: 45-83

Machado N., Schrank A., Abreu F.R., Knauer L.G., Almeida-Abreu P.A., 1989. Resultados preliminares da geocronologia U-Pb na
Serra do Espinhaço Meridional. In: SBG, Núcleo Minas Gerais, Boletim Informativo, 10: 171-174.

Noce C.M., Pedrosa-Soares A.C., Silva L.C., Alkmim F.F., 2007. O embasamento arqueano e paleoproterozóico do Orógeno Araçuaí. Geonomos 15(1): 17 - 23.

Pearce J.A., Harris N.B.W., Tindle A.G. 1984. Trace element discrimination diagrams for the tectonic interpretation of granitic rocks. Journal of Petrology, 25: 956-983.

Prado, E.S., Barros, M.A.S., Pinho, F.E.C., Pierosan, R. 2013. Granito Terra Nova - petrologia e geocronologia: um granito tipo-A da província aurífera Alta Floresta- craton Amazônico. Brazilian Journal of Geology, 43(1): 101-116.

Silva L.C., Armstrong R., Noce C.M, Carneiro M.A., Pimentel M.M., Pedrosa-Soares A.C., Leite C.A., Vieira V.S., Silva M.A., Paes V.J.C., Cardoso-Filho J.M. 2002. Reavaliação da evolução geológica em terrenos pré-cambrianos brasileiros com base em novos dados U-Pb SHRIMP, parte II: Orógeno Araçuaí, Cinturão Mineiro e Cráton São Francisco Meridional. Revista Brasileira de Geociências, 32: 513-528.

Teixeira, N.P., Bettencourt, J.S., Dall'agnol, R., Moura, C.A.V., Fernandes, C.M.D., Pinho, S.C.C. 2005. Geoquímica dos granitos paleoproterozoicos da suíte granítica Velho Guilherme, província estanífera do sul do Pará. Revista Brasileira de Geociências, 35(2): 217-226.

Xu, Y.G., Luo, Z.Y., Huang, X.L., He, B., Xiao, L., Xie, L.W., Shi, Y.R. 2008. Zircon $\mathrm{U}-\mathrm{Pb}$ and $\mathrm{Hf}$ isotope constraints on crustal melting associated with the Emeishan mantle plume. Geochimica et Cosmochimica Acta 72: 3084-3104. 